Supporting Information

\title{
Microwave-assisted efficient fructose-HMF conversion in water over sulfonated carbon microsphere catalyst
}

\author{
Xianghai Kong ${ }^{\mathrm{a}, 1}$, Srinivasan Vinju Vasudevan ${ }^{\mathrm{a}, 1}$, Mengjie $\mathrm{CaO}^{\mathrm{a}}$, Jin Cai ${ }^{\mathrm{a}}$, Hanping \\ $\mathrm{Mao}^{\mathrm{a}}$, Quan $\mathrm{Bu}^{\mathrm{a}, *}$

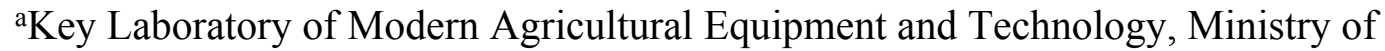 \\ Education, Jiangsu University, Zhenjiang, Jiangsu, 212013, China \\ ${ }^{1}$ Co-first author, Xianghai Kong and Srinivasan Vinju Vasudevan contributed equally to \\ this article \\ *Corresponding author, Phone: +86-511-88797338, E-mail: qbu@ujs.edu.cn \\ Number of pages: 4 \\ Number of figures: 5
}




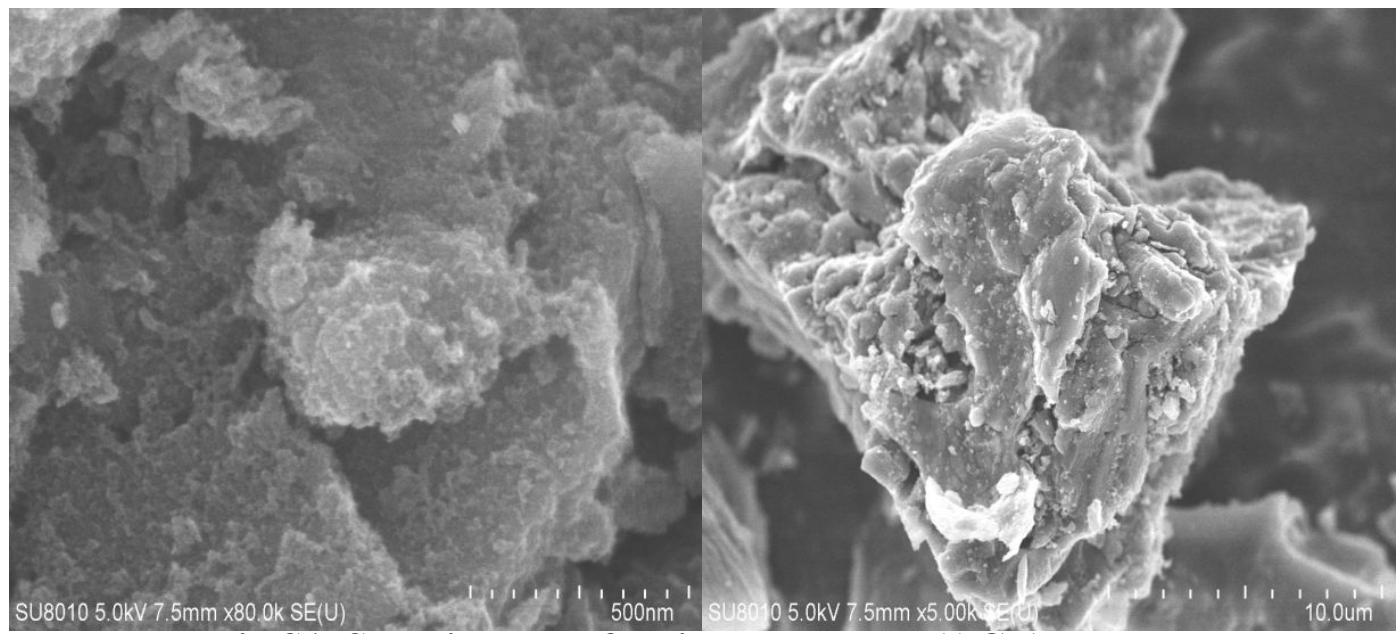

Fig S1. SEM images of activated carbon (ACT) catalyst

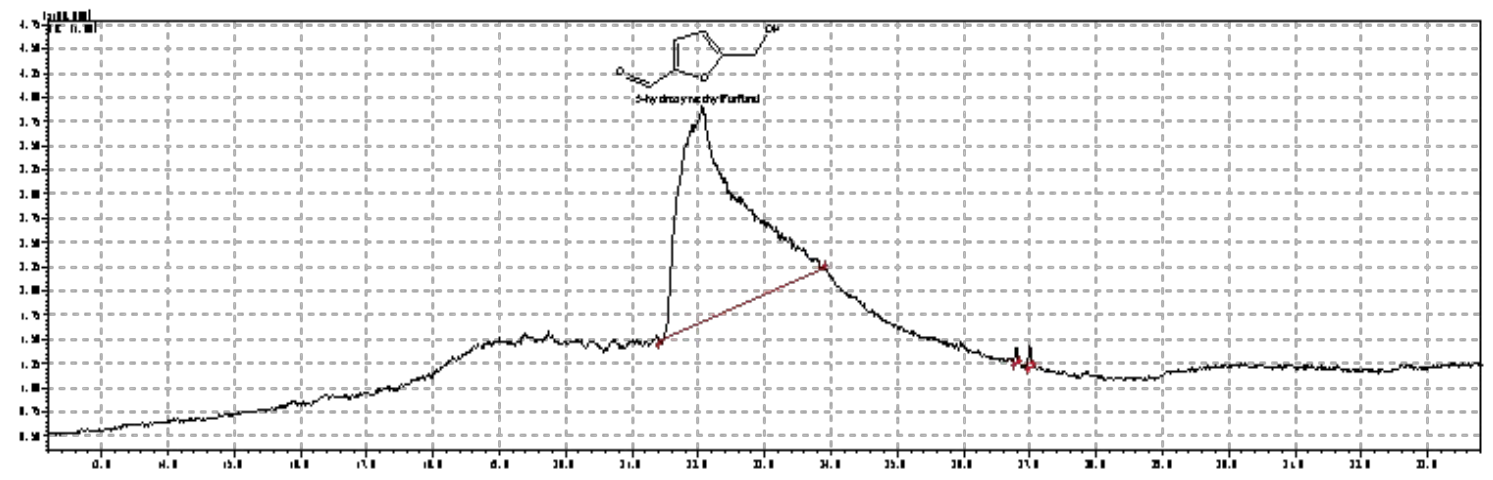

Fig. S2. Detection of reaction products by GC-MS. Reaction condition: [fructose] = $5 \mathrm{mmol},[\operatorname{SHCS}(6 \mathrm{M})]=100 \mathrm{mg}$, input power $=60 \mathrm{~W}$, time $=10 \mathrm{~min}, \mathrm{~T}=$ System equilibrium temperature

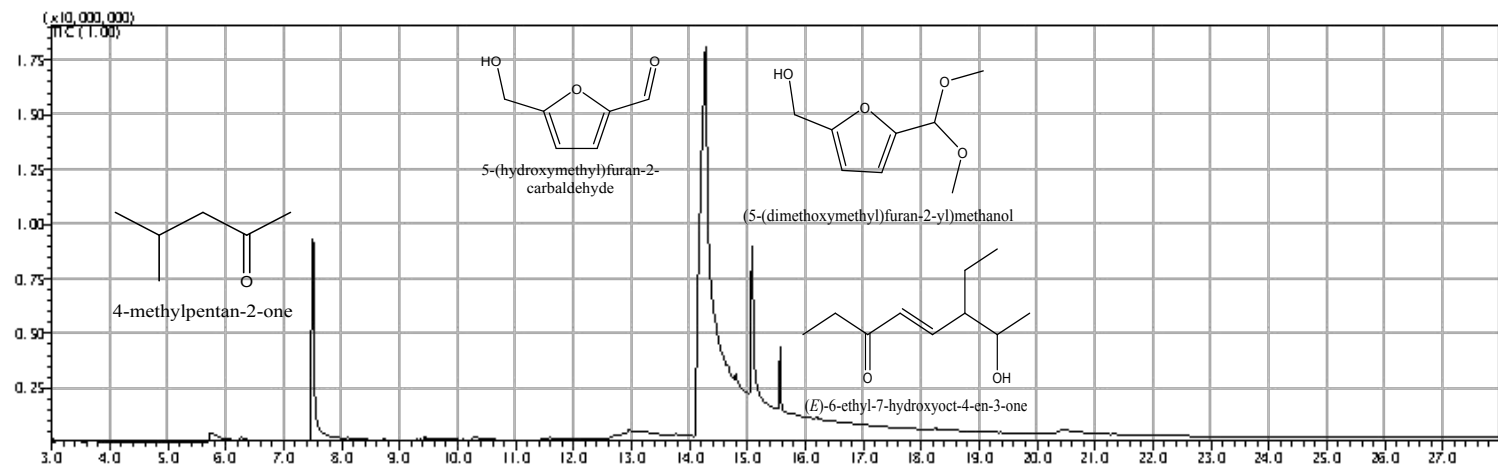


Fig. S3. Detection of reaction products by GC-MS. Reaction condition: [fructose] = $5 \mathrm{mmol}$, $[\mathrm{SHCS}(9 \mathrm{M})]=100 \mathrm{mg}$, input power $=60 \mathrm{~W}$, time $=10 \mathrm{~min}, \mathrm{~T}=$ System equilibrium temperature

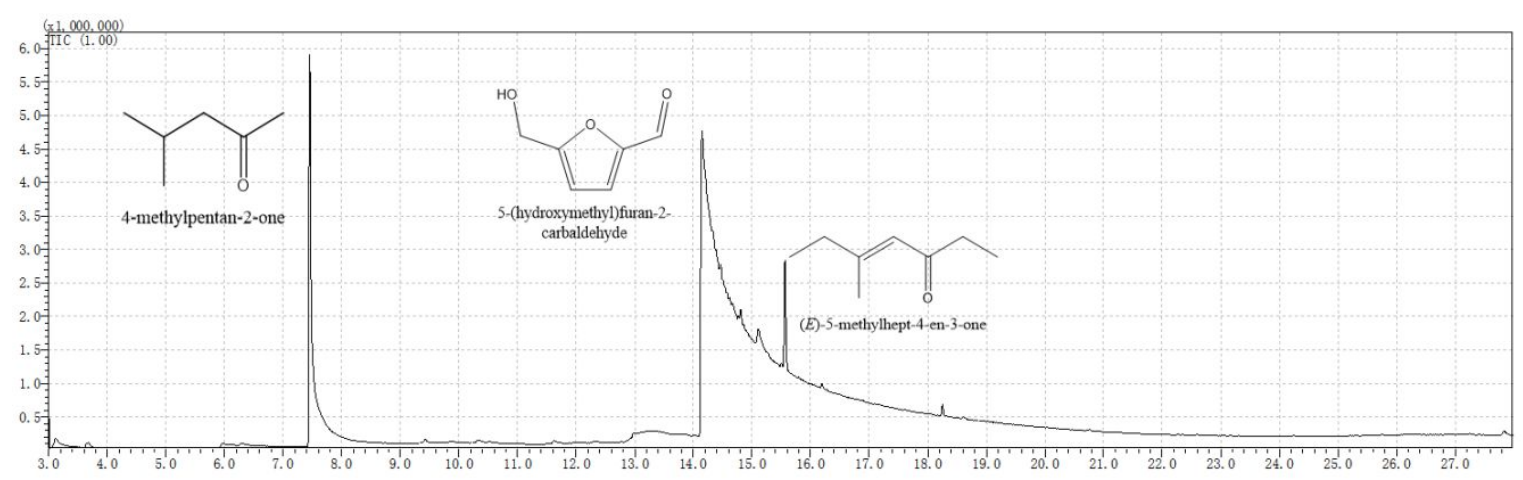

Fig. S4. Detection of reaction products by GC-MS. Reaction condition: [fructose] = $5 \mathrm{mmol}$, [SHCS $(12 \mathrm{M})]=100 \mathrm{mg}$, input power $=60 \mathrm{~W}$, time $=10 \mathrm{~min}, \mathrm{~T}=$ System equilibrium temperature

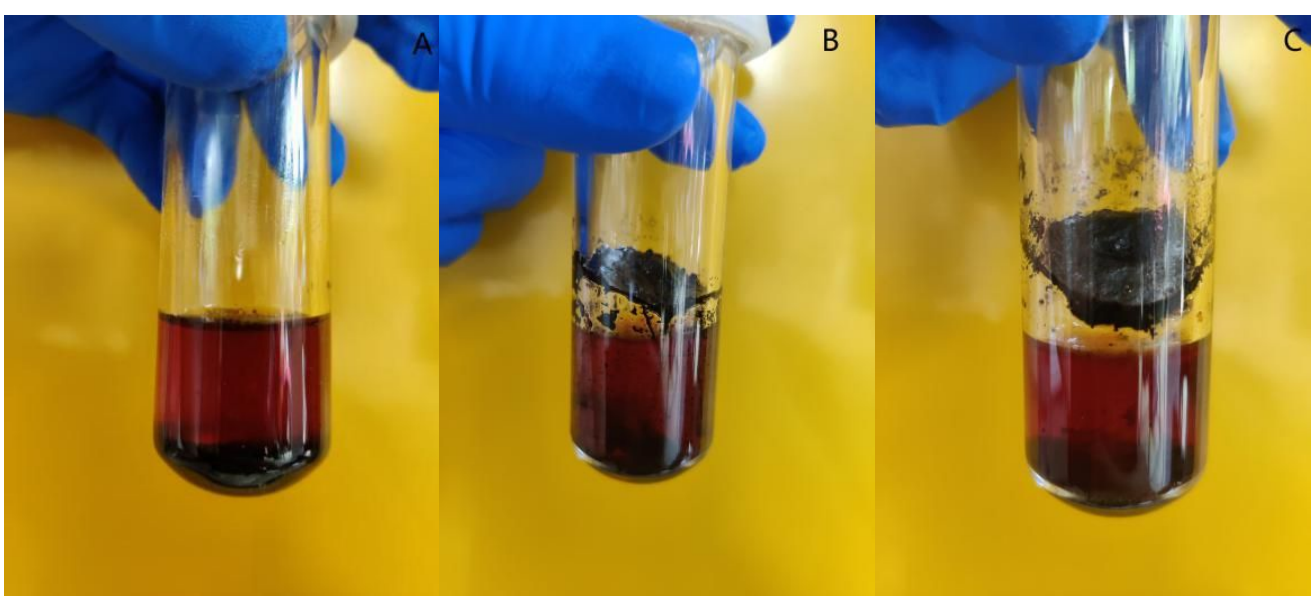




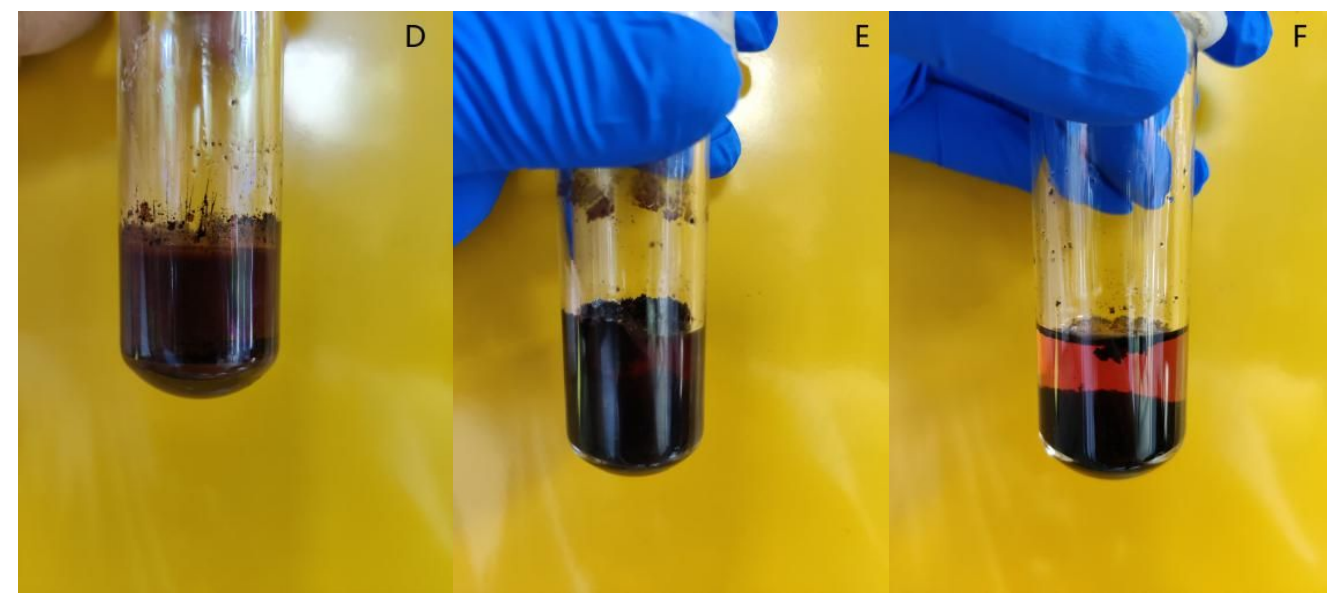

Fig. S5. The influence of the type of catalyst on the preparation of HMF carbonization by microwave catalysis (A. SHCS(6M), B. $\mathrm{HCl}, \mathrm{C}_{2} \mathrm{H}_{2} \mathrm{SO}_{4}$, D. No catalyst, E. SHC(3M), F. ATC) 